\title{
Minimal invasive surgery during COVID-19 pandemic: A review of current and emerging evidence
}

\author{
Jayan Dewantha Jayasinghe, Mohamed Adnan Thaha \\ The Royal London hospital, United Kingdom
}

Keywords: COVID-19; laparoscopy; surgical smoke; smoke evacuation; viral transmission

\section{Summary}

The COVID-19 pandemic has necessitated restructuring of surgical care globally. Concerns were raised about the continued practice of minimally invasive surgery (MIS) during the pandemic due to risk of viral transmission especially from pneumoperitoneum. As the pandemic progressed, some of the initial recommendations to address this concern were revised and some centres have gradually resumed offering MIS for a select group of patients. This is a commentary on global recommendations and guidelines on laparoscopy since the beginning of the pandemic including eight published guidelines and six original articles. Currently, there is no convincing evidence to support increased risk of viral transmission during minimally invasive compared to open surgery. Laparoscopy is still considered a safe approach during the COVID-19 pandemic when undertaken by experienced surgeons. However, judicious case selection, modification to standard practices with additional safety precautions is universally recommended.

\section{Background}

In December 2019, an outbreak of COVID-19, an acute severe respiratory syndrome was first reported in Wuhan, China. Subsequently, it was identified that COVID-19 was due to a novel corona virus named as SARS-CoV-2. On the 11th of March 2020, WHO declared a global pandemic when disease has spread to more than 210 countries and territories [1]. SARS-CoV-2 is a RNA virus, which ranges from 0.06 to 0.14 micron in size, and has been found within the cells lining the respiratory tract from nasopharynx downwards and gastrointestinal tract from mouth to anus. The virus has been found in nasal swabs, saliva, sputum, throat swabs, blood, bile, faeces with multiple modes of viral transmissions [2]. The exponential increase in the number of hospital admissions, particularly those requiring critical care supports including ventilator support required alterations in all aspects

Correspondence: Jayan Dewantha Jayasinghe

E-mail: jayan.jayasinghe@nhs.net

(iDhttps://orcid.org/0000-0003-3929-2699

Received: 14-07-2020 Accepted: 30-08-2020 DOI: http://doi.org/10.4038/sljs.v38i2.8718

The Sri Lanka Journal of Surgery 2020; 38(2): 65-68 of medical care delivery. This change was pronounced in surgical care with abolition of all elective and non-urgent surgery initially guided by local hospital policies, mainly to protect and maintain capacity. The role of minimally invasive surgery (MIS) was questioned and the heightened risks of viral transmission during MIS were debated. Since then, the emerging guidelines and national/international policies have largely guided refinement of surgical provisions including the continued offering of MIS during the pandemic.

\section{Evolving guidelines on MIS}

The initial response from the Royal College of surgeons (RCS) in United Kingdom was to delay all elective surgery including all non-urgent oncological resections. Further, it was advised against all MIS including laparoscopy, roboticassisted and trans-anal procedures [3]. As a result, most centres across the United Kingdom stopped offering both elective and emergency laparoscopic procedures including diagnostic laparoscopy and laparoscopic appendicectomy. But the updated RCS intercollegiate guidelines on 7th of April considered laparoscopy only in selected individuals where benefits outweigh the risks [4].

Society of American gastrointestinal and endoscopic surgeons (SAGES) and its European counterpart, European association of Endoscopic surgery (EAES) has jointly issued a revised guideline recognising the potential benefits of laparoscopy during the present pandemic [5].

The revised guidelines on safe surgery by the Royal Australasian College of surgeons on 9th of April also recognized no added risk of laparoscopy to the surgical team, however recommended the safe capture of surgical plume during all procedures [6].

Also, a recent U.S. joint professional society statement on minimally invasive gynaecology during the COVID-19 pandemic and the European joint society of gynaecology statements endorsed laparoscopy as a safe surgical approach in the present setting $[7,8]$.

Benefits and risks of MIS during the COVID-19 pandemic Laparoscopy offers faster recovery, reduced post-operative complications and shorter length of hospital stay. 
Consequently, MIS can potentially increase the hospital bed availability and reduce the risk of transmission of SARSCoV-2 virus to the patient during the shorter hospital stay [912]. Practicing safe distancing among surgical team during operation is also more feasible with MIS rather than open surgery where members standing in proximity [10-11]. At present, there is insufficient evidence to prove MIS specific risk of COVID-19 exposure to the surgical team compared to open surgery [6,9-12].

But prolong operating times, increase demand for surgical expertise, additional members of staff, complex equipment and increase intra-operative airway pressures exposing to more aerosols are some of the challenges for MIS during the pandemic [9-10]. Irrespective of open or MIS, the highest risk of aerosol generation and consequent viral transmission is during intubation and extubating of airways. Surgical plume generated by various energy devices carry a lesser risk of viral transmission [13]. However, CO2 insufflation which is a unique feature to laparoscopic and other MIS procedures, have been debated as an additional risk for generation and exposure to aerosols. This was largely based on isolation of other viruses such as human papilloma, Hepatitis-B and human immunodeficiency viral particles in surgical smoke and insufflate $\mathrm{CO} 2$ during previous studies [14-16]. Recent case reports on isolation of SARS-CoV-2 virus on peritoneal fluid is still to be widely established and multicentre studies are currently underway for more evidence [17].

The proponents of MIS argued that due to MIS being conducted in a self-contained field should in fact reduce any risks of spillage of both generated surgical smoke and contaminated body fluids rather than increase the risk of contamination. This thinking is reflected in the recent American (SAGES), Australasian (RACS) guidelines and consensus statement from association of laparoscopic surgeons of Great Britain and Ireland (ALSGBI) [5, 6, 12]. All advocates the routine use of a safe and effective smoke evacuation system to release the surgical plume during the procedure and to aid the controlled release of pneumoperitoneum at the end of procedure. Commercially available smoke evacuation systems with built in ultra-low particulate air (ULPA) filters can remove particles in air up to 0.1 microns. However, such systems are often in-built or single use, more expensive and not widely available in most settings $[6,10-12,18]$.

\section{Future of MIS during COVID-19 era}

Careful selection of patients who would benefit from a surgical interventions than non-operative alternatives, screening of all surgical patients pre-operatively for high risk exposure and symptoms of COVID-19, test to rule out COVID-19 infection high risk patients before any surgical procedures, minimising theatre staff inside the operating room and the correct use of personal protective equipment (PPE) are some of the considerations that should be given for both open and laparoscopic surgery.

Management of pneumoperitoneum both during and after the procedure, aiming to minimise the risks of viral transmission by aerosol generation require attention to detail and modifications to existing practices. Optimising port incisions to avoid air leak, reducing the number of ports used, use of balloon ports to avoid accidental port displacement, avoiding port exchanges and ensuring function of the valves for reusable ports will all help to reduce inadvertent viral transmission risks. Operating with the lowest possible insufflation pressure with minimal instrument exchanges and judicious use of electrocautery demands a higher skill set, hence in general the most senior and experienced member of the team should provide MIS to increase safety. Controlled and systematic desufflation with suction evacuation of pneumoperitoneum at the end of procedure before conversion to open, removal of ports or specimen extraction reduces the potential risks of inadvertent viral transmission. This process can be mostly reliable with automated insufflation, filtration and air evacuation systems $[18,19]$. However, these devices are costly, of single use and are not readily available in all settings, especially in developing countries.

Recently, Mintz et al. published a low-cost alternative for the commercially available smoke evacuation system to safely filter the air during MIS. This international group of surgeons representing the technology committee of the EAES used a heat and moist exchanging breathing filter removed from an ET tube or ventilators, an intravenous tubing set and two 2 connectors to develop the system [19]. The illustration is above with the permission from the authors of the original publication.

For best outcomes this should be connected to the largest port with insufflation inlet, shorter length of tube with tightly fitted connectors and should be used intermittently when smoke build during the use of energy devices and at the end of operation before removal of ports, extraction of specimen or conversion to open, whichever the step is earliest.

Integrating this system with direct, controlled suction of air into trocars and use of filtration face piece (FFP) masks during procedure can achieve comparable safety and efficacy to integrated surgical smoke evacuation systems which are expensive and not freely available. This could be an effective and easily adaptable alternative for surgical smoke and pneumoperitoneum evacuation in laparoscopic surgery during this challenging time in resource limited settings. 

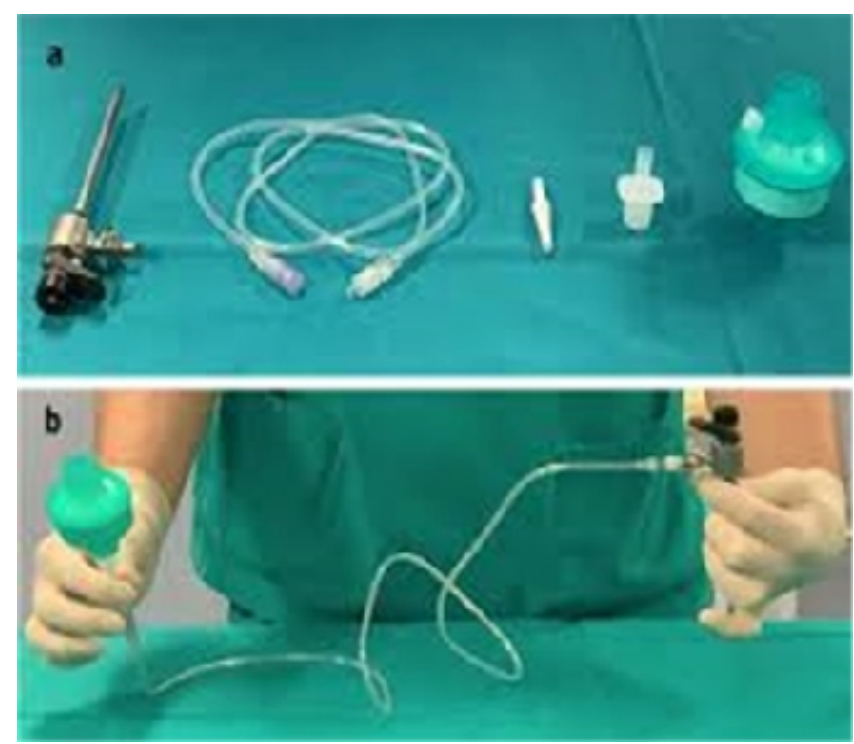

(a) Breathing filter, ET tube connector (ETC), drain tube connector (DTC), IV tubing set and laparoscopic port (cannula) with insufflation inlet

(b) System made with connecting screwed end of IV tub to insufflation inlet of the port and other end to the small side of ETC using DTC for tight fitting. Larger end of ETC is now fixed into ventilator filter

\section{Conclusion}

With judicious case selection, modification to standard practices with additional safety precautions laparoscopy is still a safe approach during the COVID-19 pandemic.

All authors disclose no conflict of interest. The study was conducted in accordance with the ethical standards of the relevant institutional or national ethics committee and the Helsinki Declaration of 1975, as revised in 2000

\section{References}

1. World Health Organization. Pneumonia of Unknown CauseChina (2020). Available at :

https://www.who.int/csr/don/05-january-2020-pneumoniaofunknown-cause-china/en/

2. Lu R, Zhao X, Li J, Niu P, et al: Genomic characterisation and epidemiology of 2019 novel coronavirus: implications for virus origins and receptor binding. Lancet 2020; 395(10224):565-574. doi: 10.1016/S0140-6736(20) 30251-8

3. Intercollegiate General Surgery Guidance on COVID-19. https://www.rcseng.ac.uk/coronavirus/joint-guidance-forsurgeons-v1/

4. The Royal College of Surgeons Updated Intercollegiate General Surgery Guidance on COVID-19. 2020; Available from: https://www.rcseng.ac.uk/coronavirus/joint-guidance-forsurgeons-v2/
5. SAGES AND EAES recommendations regarding surgical response to COVID-19 crisi. Joint SAGES and EAES guidelines on COVID-19 and MIS. https://eaes.eu/joint-sages-and-eaesguidelines-on-covid-19-and-mis/

6. Guidelines for safe surgery: open versus laparoscopic, A rapid review commissioned by RACS.

https://umbraco.surgeons.org/media/5214/2020-04-15recommendations-on-safe-surgery-laparoscopic-vs-open.pdf

7. Joint Statement in Minimally Invasive Gynecologic Surgery during the COVID-19 Pandemic. AAGL.

https://www.aagl.org/news/covid-19-joint-statement-onminimally-invasive-gynecologicsurgery/2

8. Joint RCOG/BSGE Statement on gynaecological laparoscopic procedures and COVID-19 https://www.bsge.org.uk/news/jointrcog-bsge-statement-on-gynaecological-laparoscopic procedures-and-covid-19/

9. Zheng MH, Boni L, Fingerhut A: Minimally Invasive Surgery and the Novel Coronavirus Outbreak: Lessons Learned in China and Italy. Ann Surg. 2020 Mar 26:

https://doi: 10.1097/SLA.0000000000003924

10 Vigneswaran Y, et al. What Is the Appropriate Use of Laparoscopy over Open Procedures in the Current COVID-19 Climate? J Gastrointest Surg. 2020 Apr 13: 1-6. PMID: 32285338. https://doi.org/10.1007/s11605-020-04592-9

11.N. G. Mowbray, J. Ansell, J. Horwood, J.Cornish et al. Safe management of surgical smoke in the age of COVID-19. BJS open access April, 2020

https://bjssjournals.onlinelibrary.wiley.com/doi/pdf/10.1002/ bjs. 11679

12.Laparoscopy in the COVID-19 environment-ALSGBI position statement. https://www.alsgbi.org/2020/04/22/laparoscopy-inthe-covid-19-environment-ALSGBI-position-statment/

13.Wax RS, Christian MD. Practical recommendations for critical care and anesthesiology teams caring for novel coronavirus (2019-nCoV) patients. Can J Anaesth. 2020 Feb 12; https://link.springer.com/article/10.1007\%2Fs12630-02001591-x

14.Choi SH, Kwon TG, Chung SK, Kim TH. Surgical smoke may be a biohazard to surgeons performing laparoscopic surgery. Surg Endosc2014; 28 (8): 2374-80

15.In SM, Park DY, Sohn IK, et al. Experimental study of the potential hazards of surgical smoke from powered instruments. $\mathrm{Br}$ J Surg2015; 102:1581-1586

16.Kwak HD, Kim SH, Seo YS, et al. Detecting hepatitis B virus in surgical smoke emitted during laparoscopic surgery. Occup Environ Med 2016; 73:857—863

17.Barberis A, Rutigliani M, Belli F, et al. SARS Cov 2 in peritoneal fluid: an important finding in the Covid_19 pandemic. Br J Surg2020; https://doi.org/10.1002/bjs.11816 
18. Resourses for smoke and gas evacuation during open, laparoscopic and endoscopic procedures.

https://www.sages.org/resources-smoke-gas-evacuation-duringopen-laparoscopic-endoscopic-procedures
19.Mintz Y, Arezzo A, Boni L, Chand M, Brodie R, Fingerhurt A. A Low Cost, Safe and Effective Method for Smoke Evacuation in Laparoscopic Surgery for Suspected Coronavirus Patients. Ann Surg. 2020 April 02:

https://DOI:10.1097/SLA.0000000000003965. 